\title{
Asymmetric hydrodynamic roll gap model and its experimental validation
}

\author{
Martin Müller ${ }^{1}$ - Andreas Steinboeck ${ }^{2}$ - Katharina Prinz ${ }^{1}$ - Andreas Ettl ${ }^{1}$ - Andreas Kugi ${ }^{1} \cdot$ Kurt Etzelsdorfer $^{3}$. \\ Stefan Fuchshumer ${ }^{3} \cdot$ Hannes Seyrkammer ${ }^{3}$
}

Received: 6 April 2018 / Accepted: 21 August 2018 / Published online: 25 October 2018

(C) The Author(s) 2018

\begin{abstract}
In tandem hot strip rolling mills, different friction between the rolls and the strip material on the upper and lower strip surface can occur due to asymmetric surface temperatures or different conditions of oil lubrication. To capture these effects, this paper presents a hydrodynamic roll gap model with asymmetric friction. Based on similarities between the rolled material and viscous fluids, fluid mechanics theory is used to derive this model. Due to the nature of this model, the influence of the rolling speed is inherently taken into account, which allows an accurate prediction of the rolling force and the forward slip. As an analytic solution for the hydrodynamic roll gap model is available, it is well suited for online applications in rolling plants. For validation of the proposed model, an experiment with asymmetric work roll roughness was performed. A specimen of steel strip with copper pins inserted was repeatedly rolled to visualize the material flow inside the roll gap for multiple passes. The resulting deformed copper pins were cut out of the strip and show good agreement with the deformation profiles calculated by the developed model.
\end{abstract}

Keywords Hot rolling $\cdot$ Hydrodynamic roll gap model $\cdot$ Asymmetric friction $\cdot$ Deformation profile $\cdot$ Oil lubrication

\section{Introduction}

In the steel industry, the demand for higher product quality and production speed has steadily increased during the last

Martin Müller

mueller@acin.tuwien.ac.at

Andreas Steinboeck

steinboeck@acin.tuwien.ac.at

Katharina Prinz

prinz@acin.tuwien.ac.at

Andreas Ettl

ettl@acin.tuwien.ac.at

Andreas Kugi

kugi@acin.tuwien.ac.at

1 Christian Doppler Laboratory for Model-Based Control in the Steel Industry, Automation and Control Institute (ACIN), TU Wien, Gußhausstraße 27-29, 1040 Vienna, Austria

2 Automation and Control Institute (ACIN), TU Wien, Gußhausstraße 27-29, 1040 Vienna, Austria

3 voestalpine Stahl GmbH, voestalpine-Straße 3, 4020 Linz, Austria decades. Modern model-based control concepts can make an essential contribution to meet this demand by improving the overall performance of the control loops in the rolling plant. As a result, the requirements for the mathematical models of the hot strip finishing mill also increase. In particular, the roll gap model is very important because an accurate prediction of the roll force or the forward slip is required for several applications, e.g., process planning, calculation and adjustment of nominal operating points, observers for non-measurable quantities, and advanced model-based control concepts (see, e.g., [1, 2]). In order to improve the prediction accuracy, it is essential to correctly capture the influence of various process parameters, such as rolling speed or friction between work rolls and material. Especially friction is of great interest as lubrication is often used in tandem rolling to reduce the rolling force, energy consumption, roll wear, and to increase the strip surface quality.

Due to its use in observers and control loops, the roll gap model has to fulfill certain constraints regarding the maximum allowed computation time, which may limit the achieved accuracy. Thus, tailored models with the right balance between model complexity and the required computational time have to be designed. 
In the literature, three main methods for modeling the roll gap can be found: the slab method, the upper bound method, and the finite element method (see, e.g., [3-5]).

The slab method is based on the early work of von Kármán [6] and Siebel [7]. The basic differential equations were deduced by calculating an equilibrium of forces acting on a vertical slab inside the roll gap under the assumption of homogeneous compression. It is further assumed that the vertical slab remains straight during the forming process, i.e., a vertically compressed slab is only displaced in rolling direction. Later, Orowan [8] extended this theory by considering an inhomogeneous stress field and non-uniform friction states at the surface. The major drawback of this theory is that an analytic solution is not available. This is why Sims [9] made further approximations to obtain an analytic solution. Sims' roll gap model achieves a moderately accurate prediction of the roll force and entails only low computational costs. Therefore, this model is the most commonly used roll gap model in industry. A disadvantage of Sims' model is that sticking friction is assumed over the entire arc of contact. Hence, the model cannot capture varying friction conditions or lubrication effects. Various formulations of the slab method were published that incorporate also the influence of friction (see, e.g., [10-13]). However, hardly, any attempt has been made to extend the slab method for asymmetric friction conditions (see, e.g., [14]).

The slab method has some significant drawbacks. First, the fundamental assumption of the vertical slab to maintain its rectangular shape during the whole deformation process is clearly invalid. Furthermore, the slab theory only provides a prediction of the roll force without incorporating the influence of the rolling speed, which becomes more and more important due to increasing production speeds. Consequently, the influence of the rolling speed has to be taken into account via semi-empirical material models (see, e.g., [15]) and an additional model is required to obtain the exit velocity of the steel strip.

The upper bound method is based on the extremum principles of plasticity (see [16-19]). In this method, a kinematically admissible velocity field is assumed for the deformation region and the associated dissipation energy is computed and minimized. The crucial and difficult point of this method is the choice of a kinematically admissible velocity field. In the literature, several different formulations of the velocity field in the roll gap exist (see, e.g., [20-22]). In addition to the difficulty of finding an appropriate kinematically admissible velocity field, a drawback of this method is that the predicted roll force is only an upper bound for the true value.

The most accurate prediction of the roll force can be achieved by the finite element method but at the cost of high computational effort. Over the years, many different formulations regarding material behavior and boundary conditions in the roll gap have been published (see, e.g., [3, 23, 24]). In [25], an attempt has been made to develop a finite element model that is suitable for online applications. However, the required computation time is still too high when considering modern tandem rolling mills with a strip speed above $20 \mathrm{~ms}^{-1}$. The finite element method is therefore not (yet) suitable for online applications.

In addition to the three already mentioned methods, several other theories exist (see, e.g., [26, 27]). One of the most promising is the hydrodynamic roll gap model. It was first proposed by Kneschke [28] and has recently received more attention (see, e.g., [29, 30]). Due to similarities of the material behavior of rolled products and viscous fluids, fluid mechanics theory is used to describe the deformation process. These similarities were confirmed by experiments in [31]. The capability of more accurate roll force prediction compared to Sims' model is discussed in [29, 31].

The main advantages of the hydrodynamic roll gap model are that varying friction and asymmetric rolling conditions can be described (see [32]). Despite the consideration of these process conditions, an analytic solution of the model is still available, which makes this theory well suited for online applications.

The hydrodynamic material model has already been successfully used in industry, e.g., as forward slip model in heavy plate rolling [33, 34] or in other metal forming processes like wire drawing [35].

In tandem rolling mills, asymmetric friction often occurs. Typical reasons for this undesirable effect are different surface temperatures or unequal conditions of oil lubrication on the upper and lower side of the strip. The current paper extends the hydrodynamic roll gap theory to capture also asymmetric friction conditions.

The paper is organized as follows. In Section 2, the hydrodynamic roll gap model with asymmetric friction conditions and its analytic solution are derived. In Section 3, an experimental validation of the derived model is presented. An experimental rolling mill with different roughness at the upper and lower work roll surface was used to roll a steel strip with copper pins inserted. These copper pins were used to measure and visualize the deformation caused by the velocity field inside the roll gap.

\section{Mathematical model}

\subsection{Roll gap geometry}

As shown in Fig. 1, the strip thickness is reduced from the entry thickness $h_{e n}$ to the exit thickness $h_{e x}$ while moving through the rolling mill. The elastic work roll deformation 


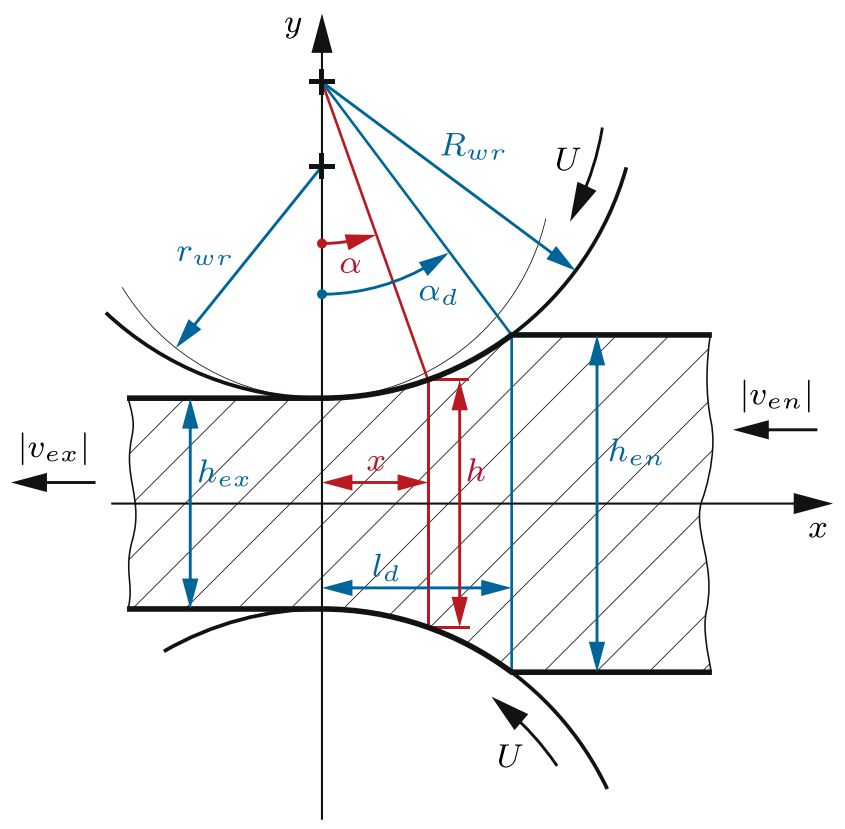

Fig. 1 Roll gap geometry

due to the distributed rolling forces is taken into account by Hitchcock's formula

$R_{w r}=r_{w r}\left(1+\frac{16\left(1-v^{2}\right)}{\pi E} \frac{P_{r o l l}}{\Delta h}\right)$

for the effective work roll radius. Here, $r_{w r}$ denotes the nominal work roll radius, $P_{\text {roll }}$ the roll force per unit width, $E$ the Young's modulus of the work roll material, and $v$ Poisson's ratio of the work roll material, see [36]. The total reduction of the strip thickness is defined as $\Delta h=h_{e n}-$ $h_{\text {ex }}$.

Let $\alpha$ be the angular coordinate that is 0 at the exit port of the roll gap and $\alpha_{d}$ at its entry port. Then, the strip thickness inside the roll gap can be written in the form

$h=h_{e x}+2 R_{w r}(1-\cos \alpha)$.

We assume small bite angles $\alpha_{d}$, so that $\sin (\alpha) \approx \alpha$ and $\cos (\alpha) \approx 1-\frac{\alpha^{2}}{2}$ holds. Using these approximations together with the relation $x=R_{w r} \sin (\alpha)$ simplifies (2) to the form

$h \approx h_{e x}+\frac{x^{2}}{R_{w r}}$.

For the length of the arc of contact, we therefore obtain

$l_{d}=\sqrt{R_{w r} \Delta h-\frac{\Delta h^{2}}{4}} \approx \sqrt{R_{w r} \Delta h}$.
To incorporate the continuity equation, it is assumed for every vertical section in the roll gap that the volume flow rate for unit strip width is given in the form

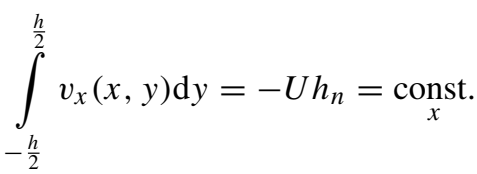

Here, $v_{x}$ is the material velocity in rolling direction, $U$ is the circumferential speed of the work roll, and $h_{n}$ is the strip thickness at the neutral plane, which will be defined later in this work. Please note that $v_{x}<0$ due to the assumption of the material flow in opposite direction of the $x$-coordinate. In Eq. 5, we assumed zero spread of the strip width $b$, i.e., a plane strain deformation regime in the $x-y$ plane. Typically, this assumption is well satisfied for $b>10 h_{e n}$ (see $[5,9]$ ).

\subsection{Hydrodynamic theory}

The hydrodynamic roll gap model with symmetric friction was first suggested by Kneschke [28, 32, 37]. This work forms the basis for the following model derivation.

The hydrodynamic rolling theory is based on the assumption of an incompressible viscoplastic material. When the equivalent stress in the deformation zone reaches the yield stress $k_{f m}$, the Navier-Stokes equation can be used to describe the material flow in the roll gap. Consequently, the total roll force consists of a static part required to reach the yield stress and a dynamic part resulting from the viscous shear stress in the material. In [31, 38-40], the validity of this separation was discussed and experimentally demonstrated.

The Navier-Stokes momentum equation for an incompressible fluid and a general point $(x, y)$ can be written in the form

$\rho\left(\frac{\partial \mathbf{v}}{\partial t}+\mathbf{v} \cdot \nabla \mathbf{v}\right)=-\nabla p_{\text {roll }}+\eta \nabla^{2} \mathbf{v}+\mathbf{f}$,

where $\mathbf{v}$ is the velocity field, $p_{\text {roll }}$ is the hydrodynamic pressure, $\mathbf{f}$ are the body forces, $\rho$ is the material density, and $\eta$ the dynamic viscosity. For the sake of readability, we omit the arguments $x, y$, and $t$ throughout this paper.

Based on the conditions in the roll gap and to facilitate an analytic solution of Eq. 6, some simplifications are made. First, a quasi-stationary state is considered, which implies $\frac{\partial \mathbf{v}}{\partial t}=\mathbf{0}$. Because the values of the body forces $\mathbf{f}$ (usually just gravity) and the convective acceleration $\mathbf{v} \cdot \nabla \mathbf{v}$ are much smaller than the other terms, $\mathbf{f}$ and $\rho \mathbf{v} \cdot \nabla \mathbf{v}$ are neglected too. It is further assumed that the bite angle $\alpha_{d}$ is small, which permits to approximate the arc of contact as slightly inclined plane surfaces and a similar ansatz as for plane-parallel plates can be used (see [37]). Thus, we neglect the velocity $v_{y}$ in vertical direction and we assume that the remaining 
component $v_{x}$ only marginally changes with respect to $x$. Using the first assumption, Eq. 6 directly yields $\frac{\partial p_{\text {roll }}}{\partial y}=0$, meaning that the pressure $p_{\text {roll }}$ is independent of $y$. The second assumption implies that $\frac{\partial^{2} v_{x}}{\partial x^{2}} \ll \frac{\partial^{2} v_{x}}{\partial y^{2}}$ holds inside the roll gap. Summarizing, Eq. 6 simplifies to the ordinary differential equation

$\frac{\partial^{2} v_{x}}{\partial y^{2}}=\frac{1}{\eta} \frac{\mathrm{d} p_{\text {roll }}}{\mathrm{d} x}$,

which is henceforth used to describe the viscous material flow in the roll gap. Assuming a material behavior like a Newtonian fluid, the shear stress follows in the form

$\tau=\eta \frac{\partial v_{x}}{\partial y}$

\subsubsection{Boundary conditions}

To derive the boundary conditions for Eq. 7, the shear stress at the contact surface between the work roll and the steel strip is used. It directly follows from evaluating (8) at $y=$ $\pm \frac{h}{2}$. Considering the differential speed between the work rolls and the material, viscous friction is assumed at the arc of contact [32]. Therefore, the boundary condition for $v_{x}$ follows in the form

$$
\begin{gathered}
\left.\left(\varepsilon_{u} \frac{\partial v_{x}}{\partial y}+v_{x}\right)\right|_{y=\frac{h}{2}}=-U \\
\left.\left(-\varepsilon_{l} \frac{\partial v_{x}}{\partial y}+v_{x}\right)\right|_{y=-\frac{h}{2}}=-U
\end{gathered}
$$

for the upper and lower arc of contact, respectively, with $h$ from Eq. 3. In this work, separate friction coefficients $\varepsilon_{u} \geq 0$ and $\varepsilon_{l} \geq 0$ are introduced in order to account for different friction at the upper and lower arc of contact. Possible causes for this asymmetric friction are different amounts of lubricant or cooling water that enter the contact area, different surface temperatures of the strip or different roughness values of the work rolls. For $\varepsilon=0$, the material velocity at the surface equals the circumferential speed of the work roll. This case represents a state of sticking friction. For $\varepsilon>0$, slipping friction is present. Hence, by virtue of the parameter $\varepsilon$, the model is capable of describing two different frictional states. Since the friction coefficient $\varepsilon$ as introduced in Eq. 9 has the dimension of length, alternatively, the dimensionless friction coefficients

$\gamma_{u}=\frac{6 \varepsilon_{u}}{h_{e x}}, \quad \gamma_{l}=\frac{6 \varepsilon_{l}}{h_{e x}}$

can be used (see [32]). In general, different circumferential speeds for the upper and lower work roll can be taken into account in Eq. 9. Here, however, we only consider the application in a tandem rolling mill where symmetric work roll speeds are commonly used.
The next boundary condition can be formulated by considering strip tension at the entry and exit interface of the roll gap. These distributed forces directly correspond to the hydrodynamic pressure. Thus, the boundary condition for the pressure can be written in the form

$$
\begin{aligned}
& p_{\text {roll }}(0)=-p_{\text {ex }} \\
& p_{\text {roll }}\left(l_{d}\right)=-p_{\text {en }}
\end{aligned}
$$

with the strip tension $p_{e n}$ and $p_{e x}$ at the entry and exit side, respectively.

Summarizing, the material deformation inside the roll gap is described by the simplified Navier-Stokes equation from Eq. 7 with the boundary conditions in Eqs. 9 and 11 for the velocity and the hydrodynamic pressure.

\subsubsection{Solution of the PDE}

The velocity field follows from integrating (7) along the direction $y$ and inserting the boundary conditions (9). Thus, we obtain

$$
\begin{aligned}
v_{x}(x, y)= & \frac{1}{2 \eta} \frac{\mathrm{d} p_{\text {roll }}}{\mathrm{d} x}\left(y^{2}-\frac{h\left(\varepsilon_{u}-\varepsilon_{l}\right)}{h+\varepsilon_{u}+\varepsilon_{l}} y\right. \\
& \left.-\frac{h}{4} \frac{h^{2}+3\left(\varepsilon_{u}+\varepsilon_{l}\right) h+8 \varepsilon_{u} \varepsilon_{l}}{h+\varepsilon_{u}+\varepsilon_{l}}\right)-U .
\end{aligned}
$$

Equation 12 shows that the velocity field $v_{x}$ has a parabolic shape in vertical direction $y$. In case of equal values of the upper and lower friction coefficients, i.e., $\varepsilon_{u}=\varepsilon_{l}$, the velocity field is symmetric with respect to the line $y=0$. Figure 2 shows typical velocity fields in case of symmetric

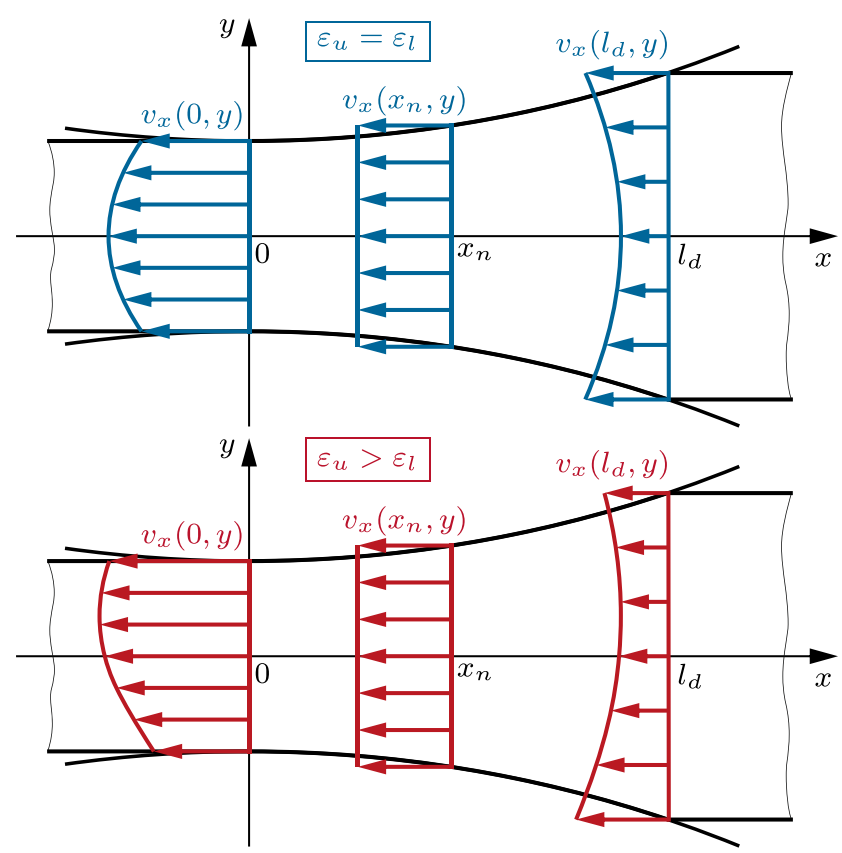

Fig. 2 Parabolic distribution of the velocity field inside the roll gap for symmetric (top) and asymmetric (bottom) friction conditions 
$\left(\varepsilon_{u}=\varepsilon_{l}\right)$ and asymmetric $\left(\varepsilon_{u}>\varepsilon_{l}\right)$ friction conditions for the entry, neutral, and exit plane.

Insertion of Eq. 12 into the continuity equation (5) gives the differential equation of the hydrodynamic pressure

$\frac{\mathrm{d} p_{\text {roll }}}{\mathrm{d} x}=\frac{12 \eta}{h^{2}} \frac{\left(h_{n}-h\right)\left(h+\varepsilon_{u}+\varepsilon_{l}\right)}{\left(h^{2}+4\left(\varepsilon_{u}+\varepsilon_{l}\right) h+12 \varepsilon_{u} \varepsilon_{l}\right)} U$.

Integration of this relation along $x$ and inserting the boundary condition (11a) yields the pressure distribution

$$
\begin{aligned}
p_{\text {roll }}=p_{\text {ex }} & +\frac{\eta U}{\varepsilon_{u} \varepsilon_{l}}\left(\left(\phi_{1,1} h_{n}+\phi_{1,2}\right) \psi_{1}\right. \\
& +\left(\phi_{2,1}^{+} h_{n}+\phi_{2,2}^{+}\right) \psi_{2}^{+} \\
& +\left(\phi_{2,1}^{-} h_{n}+\phi_{2,2}^{-}\right) \psi_{2}^{-} \\
& \left.+h_{n} \psi_{3}\right)
\end{aligned}
$$

with the abbreviations

$$
\begin{aligned}
\phi_{1,1} & =-\frac{1}{3} \chi^{2}+\frac{1}{2 h_{e x}} \varepsilon_{u} \varepsilon_{l}\left(\varepsilon_{u}+\varepsilon_{l}\right) \\
\phi_{1,2} & =\varepsilon_{u} \varepsilon_{l}\left(\varepsilon_{u}+\varepsilon_{l}\right) \\
\psi_{1} & =\frac{\sqrt{R_{w r}} \arctan \frac{x}{\sqrt{h_{e x} R_{w r}}}}{\varepsilon_{u} \varepsilon_{l} \sqrt{h_{e x}}} \\
\phi_{2,1}^{ \pm} & =\frac{1}{6}\left(\chi^{3} \pm\left(\varepsilon_{u}+\varepsilon_{l}\right)\left(\chi^{2}-\frac{3}{2} \varepsilon_{u} \varepsilon_{l}\right)\right) \\
\phi_{2,2}^{ \pm} & =\frac{\varepsilon_{u} \varepsilon_{l}}{2}\left(\left(\varepsilon_{u}+\varepsilon_{l}\right) \chi \pm\left(\chi^{2}-3 \varepsilon_{u} \varepsilon_{l}\right)\right) \\
\psi_{2}^{ \pm} & =\frac{\sqrt{R_{w r}} \arctan \frac{x}{\sqrt{R_{w r}} \sqrt{h_{e x}+2\left(\varepsilon_{u}+\varepsilon_{l}\right) \pm 2 \chi}}}{\varepsilon_{u} \varepsilon_{l} \chi \sqrt{h_{e x}+2\left(\varepsilon_{u}+\varepsilon_{l}\right) \pm 2 \chi}} \\
\psi_{3} & =\frac{R_{w r}\left(\varepsilon_{u}+v_{x}\right) x}{h_{e x}\left(R_{w r} h_{e x}+x^{2}\right)}
\end{aligned}
$$

and $\chi=\sqrt{\varepsilon_{u}^{2}-\varepsilon_{u} \varepsilon_{l}+\varepsilon_{l}^{2}}$. Note that $\phi .$, depends on $\varepsilon_{u}$ and $\varepsilon_{l}$ whereas $\psi$. depends on $\varepsilon_{u}, \varepsilon_{l}$, and $x$.

Insertion of (14a) into the boundary condition (11b) yields

$$
\begin{aligned}
h_{n}= & \frac{\phi_{1,2} \psi_{1}\left(l_{d}\right)+\phi_{2,2}^{+} \psi_{2}^{+}\left(l_{d}\right)+\phi_{2,2}^{-} \psi_{2}^{-}\left(l_{d}\right)+\psi_{3}\left(l_{d}\right)}{\phi_{1,1} \psi_{1}\left(l_{d}\right)+\phi_{2,1}^{+} \psi_{2}^{+}\left(l_{d}\right)+\phi_{2,1}^{-} \psi_{2}^{-}\left(l_{d}\right)} \\
& +\frac{\varepsilon_{u} \varepsilon_{l}}{\eta U} \frac{p_{e x}-p_{e n}}{\phi_{1,1} \psi_{1}\left(l_{d}\right)+\phi_{2,1}^{+} \psi_{2}^{+}\left(l_{d}\right)+\phi_{2,1}^{-} \psi_{2}^{-}\left(l_{d}\right)}
\end{aligned}
$$

Using Eq. 3 , the position of the neutral plane $x_{n}$ can easily be determined with $h_{n}$ from Eq. 15. The first term in Eq. 15 gives the position of the neutral plane when no strip tension is present and the second term describes its displacement due to the strip tension on the entry and exit side. Considering (13), the neutral plane is characterizing the position of the maximum value of the hydrodynamic pressure. Furthermore, the material velocity at the neutral plane equals the work roll circumferential speed and is uniformly distributed in vertical direction, i.e., $v_{x}\left(x_{n}, y\right)=$ $-U$.

Finally, insertion of Eqs. 15 and 13 into Eqs. 12 and 14a gives the complete solution of the velocity field and the hydrodynamic pressure in the roll gap. Besides the hydrodynamic pressure acting along the normal direction of the strip-roll contact surface, the tangential shear stress $\tau$ is required to fully describe the force interaction between the work roll and the material. The relation for the shear stress follows from applying (12) with $y= \pm \frac{h}{2}$ to Eq. 8 and reads as

$$
\tau\left(x, \pm \frac{h}{2}\right)=\left( \pm \frac{h}{2}-\frac{h}{2} \frac{\varepsilon_{u}-\varepsilon_{l}}{h+\varepsilon_{u}+\varepsilon_{l}}\right) \frac{\mathrm{d} p_{\text {roll }}}{\mathrm{d} x} .
$$

\subsubsection{Rolling force}

The total rolling force $P_{\text {roll }}=P_{s t}+P_{d y n}$ is the sum of two parts, namely the static part $P_{s t}$ to reach the yielding state of the material and the dynamic part $P_{d y n}$ associated with the hydrodynamic forces at the arc of contact. In this work, all forces are normalized for unit strip width.

The static force $P_{s t}$ is assumed as uniaxial force in vertical direction. In order to reach the yielding state of the material, the resulting uniformly distributed normal stress is required to be equal to the yield stress $k_{f m}$. Hence, the static part of the roll force calculates as

$P_{s t}=\int_{0}^{l_{d}} k_{f m} \mathrm{~d} x=k_{f m} l_{d}$.

The dynamic part takes into account the hydrodynamic pressure and the shear stress (see Eqs. 14a and 16, respectively). The resulting forces at the work roll surface are depicted in Fig. 3. By using the free-body principle the force in radial direction reads as $p=p_{\text {roll }} R_{w r} \mathrm{~d} \alpha$ and the tangential force follows in the form $q=-\tau\left(x, \pm \frac{h}{2}\right) R_{w r} \mathrm{~d} \alpha$.

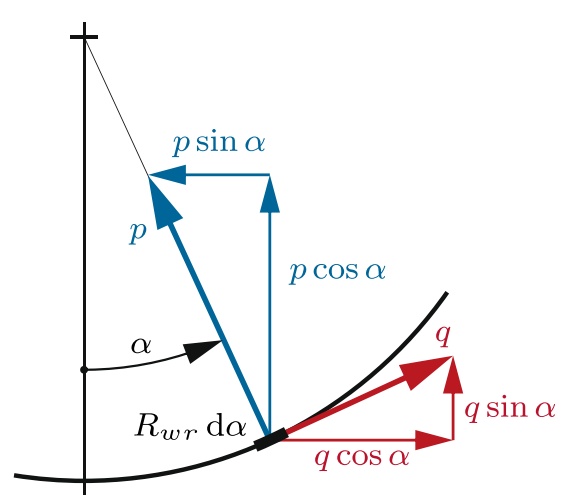

Fig. 3 Forces at the work roll surface 
Hence, the vertical component of the dynamic part is given by

$P_{d y n}=R_{w r} \int_{0}^{\alpha_{d}} p_{\text {roll }} \cos \alpha-\tau\left(x, \pm \frac{h}{2}\right) \sin \alpha \mathrm{d} \alpha$.

In [37], Kneschke uses the approximations $\sin (\alpha) \approx \alpha$ and $\cos (\alpha) \approx 1-\frac{\alpha^{2}}{2}$ for the trigonometric functions in Eq. 18. In [32], however, Kneschke and Bandemer even use the approximations $\cos (\alpha)=1$ and $\sin (\alpha)=0$. This implies that the contribution of the shear stress is completely omitted and the dynamic part of the rolling force is computed in the form

$P_{d y n}=\int_{0}^{l_{d}} p_{r o l l} \mathrm{~d} x$

Remark 1 In a tandem finishing mill, the strip material is subject to significantly varying temperatures, strains, and rolling speeds. It is well known that these changing conditions are causing variations of the material parameters. The material might even undergo warm deformation regions where, e.g., strain hardening, dynamic recovery or recrystallization may occur. To incorporate these effects in the hydrodynamic roll gap model, the material parameters $k_{f m}$ and $\eta$ can be described using tailored material models similar to the commonly used flow curve functions (see, e.g., [15]). These material models can describe the evolution of the material parameters from the first to the last mill stands. Compared to flow curve functions for slabmethod-based roll gap models, the material models for the hydrodynamic roll gap model only require a reduced set of influencing variables because the hydrodynamic model already captures the influence of the rolling speed.

Local changes of the material parameters within the roll gap, e.g., caused by, through-thickness temperature gradients, result in a more complex PDE and the analytic solvability is likely to be lost. However, the practically most important output of this roll gap model is the roll force, which is an integral quantity and thus less sensitive to locally changing parameters. Therefore, it is reasonable to use effective (mean) values of the material parameters. The hydrodynamic roll gap model was already used together with semi-empirical material models for effective material parameters in [41], where a significantly higher prediction accuracy for the roll force was achieved compared to Sims' model.

The calculation of the material parameters using material models as well as the calculation of their effective (averaged) values requires the strip temperature (and its through-thickness distribution) as an input. For application in a rolling plant, this temperature input can be provided by using temperature measurements, models, or observers (see, e.g., [42-44]).

\subsection{Deformation profile}

Consider that a material particle of the strip travels along the path $x=\zeta_{x}(t)$ and $y=\zeta_{y}(t)$ and let $x_{0}=\zeta_{x}(0)$ and $y_{0}=\zeta_{y}(0)$ be its initial position. Then, $\zeta_{x}(t)$ and $\zeta_{y}(t)$ can be computed by integration of the initial value problem

$\begin{aligned} \frac{\mathrm{d} \zeta_{x}(t)}{\mathrm{d} t} & =v_{x}\left(\zeta_{x}(t), \zeta_{y}(t)\right) \\ \frac{\mathrm{d} \zeta_{y}(t)}{\mathrm{d} t} & =v_{y}\left(\zeta_{x}(t), \zeta_{y}(t)\right)\end{aligned}$

with $\zeta_{x}(0)=x_{0}$ and $\zeta_{y}(0)=y_{0}$. However, because $v_{y}$ is not explicitly computed in the considered roll gap model, the reasonable assumption

$y(x)=y\left(l_{d}\right) \frac{h}{h_{e n}}$

is made for the respective path. Hence, Eq. 20 simplifies to the form

$$
\begin{aligned}
\frac{\mathrm{d} \zeta_{x}(t)}{\mathrm{d} t} & =v_{x}\left(\zeta_{x}(t), y\left(\zeta_{x}(t)\right)\right) \\
\zeta_{y}(t) & =y\left(\zeta_{x}(t)\right)
\end{aligned}
$$

After inserting (12), this equation can be integrated using any solver for initial value problems.

To obtain the required deformation profile, multiple paths $\zeta_{x, i}(t), i=1, \ldots, N$ with different initial vertical positions $y_{0, i}$ equally distributed over the strip height are calculated. The deformation profile at the time $t>0$ is then written in the form

$\mathbf{d}(t)=\left[\zeta_{x, 1}(t), \zeta_{x, 2}(t), \ldots, \zeta_{x, N}(t)\right]^{\mathrm{T}}$.

Furthermore, the initial displacements $x_{0, i}$ can be set accordingly for each path $\zeta_{x, i}(t)$ in order to incorporate an initial deformation from a previous roll pass.

Equation 12 defines the velocity field only in the computational domain $x \in\left[0, l_{d}\right]$ of the hydrodynamic roll gap model. For regions $x<0$ and $x>l_{d}$, the hydrodynamic roll gap model does not define the velocity profile. Clearly, far away from the roll gap, the velocity field has the uniform upstream values $v_{e n}=-\frac{h_{n}}{h_{e n}} U$ or downstream values $v_{e x}=-\frac{h_{n}}{h_{e x}} U$. The transitions from these uniform farfield velocities to the parabolic velocity profiles $v_{x}(0, y)$ and $v_{x}\left(l_{d}, y\right)$ at the exit and entry port of the roll gap, respectively, are not captured by the hydrodynamic roll gap model. This is acceptable because the primary purpose of the hydrodynamic roll gap model is the computation of the roll force. It is plausible that this roll force is not 
significantly influenced by the velocity profile in the strip outside the roll gap.

However, the unknown velocity profiles near the roll gap would be required to accurately compute the total plastic material displacement inside the strip while it is deformed. Normally, the total material displacement is not of interest but in this paper, it will be required for validating the modelbased on copper pins inserted into and rolled with the strip (see Section 3). The shape of these pins after rolling is compared to the computed shape (total displacement) of an originally straight material line oriented along the transverse strip direction. For this computation, the (unknown) velocity profiles outside the roll gap are neglected. The error entailed by this approximation is assumed small because the neglected non-uniformities of the material velocities outside the roll gap are almost symmetrical at the entry and exit of the roll gap and thus their effects on the total material displacement neutralize each other.

\section{Experimental validation}

For validation of the proposed model, an experiment that visualizes the material deformation inside the roll gap was carried out. First, some details of the performed experiment are given in this section. Then, calculation results from the hydrodynamic model are compared to the deformation profiles obtained from the experiment.

\subsection{Experimental setup}

The experiment was conducted on a laboratory rolling mill of voestalpine Stahl $\mathrm{GmbH}$. The facility consists of a heating furnace, a single-stand reversing rolling mill, and a roller table. The work rolls are conventional ICDP (indefinite chill double pour) rolls which are also used in the finishing mill of voestalpine. The rolls have a nominal radius $r_{w r}=0.31 \mathrm{~m}$, the Young's modulus $E=175 \mathrm{kN}$ $\mathrm{mm}^{-2}$, and the Poisson's ratio $v=0.3$.

The goal of this experiment is to visualize the material flow inside the roll gap. A copper pin is inserted into the steel strip (steel grade S355J2G3/1.0570) in vertical direction and after a roll pass the strip is cut in longitudinal direction through the middle of the pin. This cut reveals the deformed copper pin, which is then graphically analyzed. To minimize the impact of different deformation resistances between the strip material and the copper pin, the pin diameter should be small compared to the entry strip thickness $h_{e n}$.

In order to examine the deformation of consecutive roll passes, which for instance occur in tandem rolling mills, additional copper pins are inserted with a total count equal to the number of roll passes. After each roll pass one of these pins is removed, giving the total deformation due to all previous passes. Furthermore, a new pin is inserted before each roll pass and removed again immediately after this pass. This procedure gives the incremental deformation caused by the respective pass. As the removal and the insertion of copper pins is only possible at lower temperatures, the specimen is cooled down and reheated between every roll pass. This allows a sequence of decreasing rolling temperatures as it would occur during consecutive rolling passes on a tandem or reversing rolling mill. Furthermore, the reheating of the steel strip after each roll pass and the close distance between the mill stand and the furnace guarantees an almost homogeneous temperature along the strip thickness. Before entering the mill stand, the strip surface temperature is measured by using a pyrometer.

\subsection{Results}

The experiment was carried out with a total number of $n=7$ roll passes, which are specified in Table 1. Measured values are shown in the upper part of the table, whereas the values

Table 1 Experimental data for seven consecutive roll passes with measured and calculated values at the upper and lower part, respectively

\begin{tabular}{llllllll}
\hline Pass no. & & 1 & 2 & 3 & 4 & 5 & 7 \\
\hline$h_{\text {en }}$ & $(\mathrm{mm})$ & 40.02 & 26.56 & 20.28 & 15.72 & 12.19 & 9.97 \\
$h_{\text {ex }}$ & $(\mathrm{mm})$ & 26.56 & 20.28 & 15.72 & 12.19 & 9.97 & 8.14 \\
$U$ & $(\mathrm{~m} / \mathrm{s})$ & 0.8 & 1 & 1.5 & 2 & 2.5 & 3 \\
$\vartheta$ & $\left({ }^{\circ} \mathrm{C}\right)$ & 955 & 909 & 902 & 887 & 848 & 784 \\
$P_{m}$ & $(\mathrm{MN} / \mathrm{m})$ & 16.34 & 11.04 & 10.29 & 10.97 & 9.48 & 9.15 \\
& & & & & & 784 \\
$P_{\text {roll }}$ & $(\mathrm{MN} / \mathrm{m})$ & 16.33 & 11.30 & 10.44 & 10.56 & 8.98 & 9.75 \\
$\delta_{h}$ & $(\%)$ & 33.6 & 23.6 & 22.5 & 22.4 & 18.2 & 18.4 \\
$R_{w r}$ & $(\mathrm{~mm})$ & 319.9 & 324.4 & 328.5 & 335.5 & 345.1 & 3.37 \\
$l_{d}$ & $(\mathrm{~mm})$ & 65.6 & 45.1 & 38.7 & 34.5 & 27.7 & 351 \\
\hline
\end{tabular}




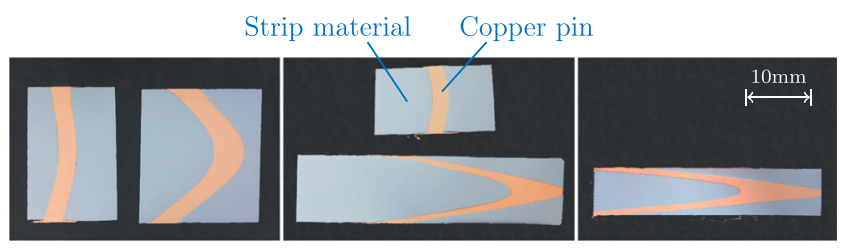

Fig. 4 Samples of incremental and absolute deformation of the copper pins after the roll passes 2 and 5, and absolute deformation after roll pass 7

in the lower part were calculated. The given rolling schedule was deduced from an actual rolling schedule of an industrial tandem finishing mill. Similar to the industrial scenario, the relative thickness reduction $\delta_{h}=\frac{h_{e n}-h_{e x}}{h_{e n}}$ and the temperature $\vartheta$ were decreased and the circumferential speed $U$ of the work rolls was increased with every consecutive pass. The measured roll force $P_{m}$ is in good accordance with the roll force $P_{\text {roll }}$ which was calculated using Eqs. 17 and 19 . The effective work roll radius $R_{w r}$ was calculated using the measured roll force.

Figure 4 shows the corresponding incremental and total deformation of the inserted copper pins after the passes 2, 5, and 7.

Figure 5 shows the cross section of copper pins after the second rolling pass. In this figure, three reference points of each copper pin are highlighted to indicate the asymmetry of the deformation. In fact, the line connecting the end points of the copper pins is inclined by $3.1^{\circ}$ and $9.7^{\circ}$ for the incremental and absolute deformation, respectively. This asymmetry can be attributed to different roughness values of the upper and lower work roll surface present in this experiment.

For the following calculations of the deformation profiles according to the hydrodynamic roll gap model, the initial value problem from Eq. 22a was solved using the MATLAB Runge-Kutta solver ode45. The quantities $v, E$, and $r_{w r}$ represent nominal parameters of the model and are assumed to be known. For the model inputs $U, h_{e n}, h_{e x}$, and $P_{m}$ the measured values from Table 1 were used. The only unknown

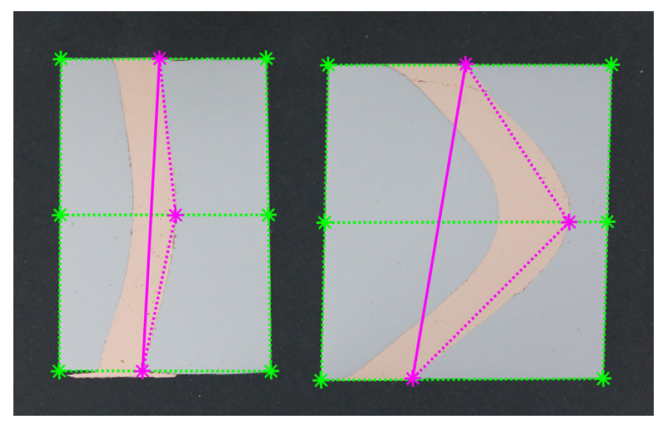

Fig. 5 Incrementally and absolutely deformed copper pins after the second roll pass with reference points indicating asymmetric deformation parameters of the model are the friction coefficients $\gamma_{u}$ and $\gamma_{l}$ (see Eq. 10) and the material parameters $k_{f m}$ and $\eta$. Due to the absence of strip tension in this experiment, the calculation of the velocity field, and thus also of the deformation profile, is independent of the material parameters. For the friction coefficients, the values $\gamma_{u}=$ 0.8 (slipping friction) and $\gamma_{l}=0$ (sticking friction) were identified for the whole experiment. This result qualitatively coincides with the roughness values of the work roll surface, as the lower work roll had a higher roughness compared to the upper work roll.

Figure 6 shows the velocity field and the resulting deformation profile calculated for the first roll pass. At the entry port of the roll gap, the near-surface region of the strip material moves faster than the material in the core. consequently, an initially straight vertical material line is bent in the course of the deformation in the roll gap. The maximum horizontal deflection of this line is reached at the neutral plane. From the neutral plane to the exit port of the roll gap, the material velocity in the core of the strip exceeds that in the near-surface region and the horizontal deflection of the considered material line reduces.

Figure 7 shows a detailed view of the deformation profile with a picture of the deformed copper pin in the background. The calculated deformation profile is in good agreement with the experiment.

The results after the second roll pass are shown in Fig. 8. It includes the velocity field $v_{x}(x, y)$ and both the relative and the absolute deformation profile $\mathbf{d}_{r e l}(t)$ and $\mathbf{d}_{a b s}(t)$ according to Eq. 23, respectively. The velocity field is similar to the first pass but the absolute velocities are higher due to an increased rolling speed. The reduction rate for the
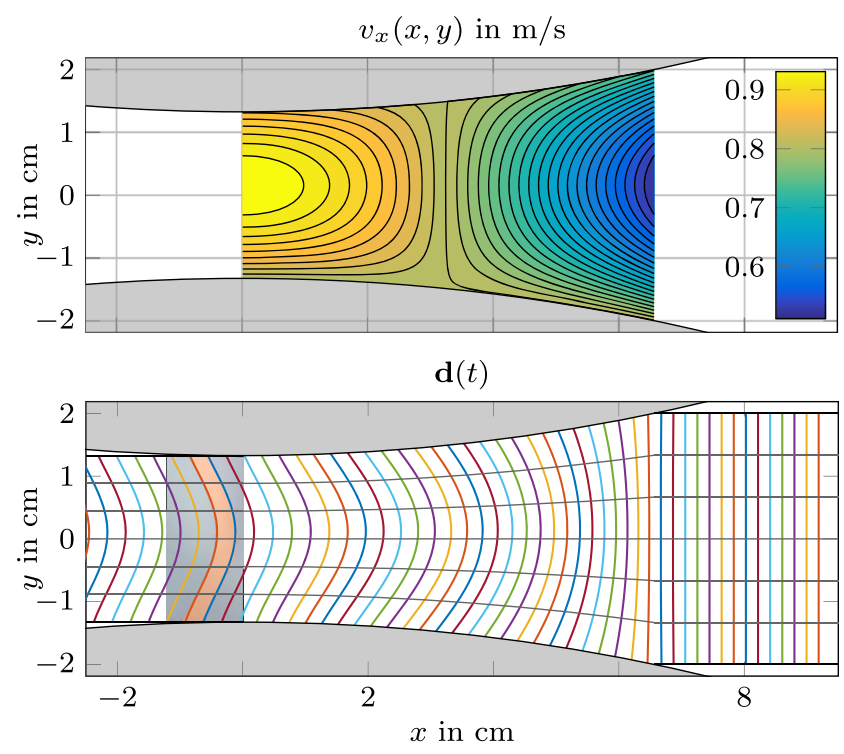

Fig. 6 Velocity field and deformation for first roll pass with friction coefficients $\gamma_{u}=0.8$ and $\gamma_{l}=0$ 


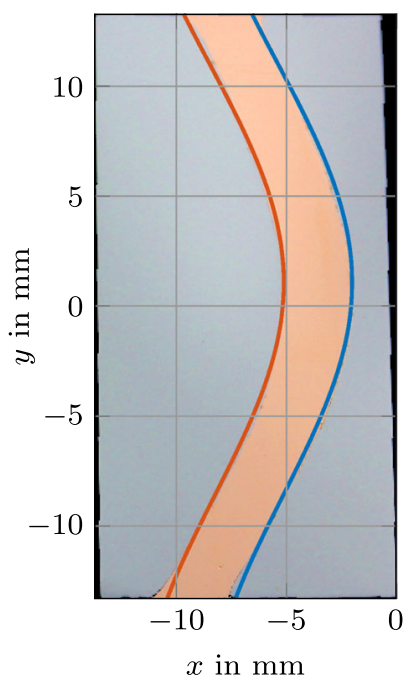

Fig. 7 Calculated deformation of initially straight material lines and the deformed copper pin after the first roll pass

second roll pass is lower than for the first pass. This is the main reason for a smaller horizontal deflection of initially straight material lines than for the first pass. Based on the continuity equation, the absolute deformation profile after the roll pass $k$ can be calculated in the form

$\mathbf{d}_{a b s, k}=\frac{h_{e n, k}}{h_{e x, k}} \mathbf{d}_{a b s, k-1}+\mathbf{d}_{r e l, k}$

using the absolute deformation $\mathbf{d}_{a b s, k-1}$ after the previous pass.

A detailed view of the calculated deformation profiles with the corresponding copper pins in the background is shown in Fig. 9. The profiles are again in good accordance with the experiment. Only near the lower surface of the strip a small deviation occurs.

With an increased number of roll passes, the front and back edges of the copper pins measuring the total deformation loose their parallelism, i.e., the pin diameter varies along the strip thickness. This problem arises due to the lower deformation resistance of copper, which also causes an outflow of copper at the top and bottom of the strip. Therefore, the mean of the front and back edge, i.e., the centerline, of the copper pin was used for further comparison with the calculated deformation profiles. To detect these edges in the bitmaps, a color segmentation algorithm was first used to create a binary image of the copper pin, then a Sobel filter was used for edge detection. Afterwards, a polynomial of degree 8 was fitted into the filtered bitmap to obtain a smooth representation of the two edges. Based on these two polynomials, the centerline of the copper pin was calculated.

The results after the roll passes 3 to 6 are also in good accordance with the experiment and the calculated velocity fields are similar to those shown in Figs. 6 and 8. Therefore,
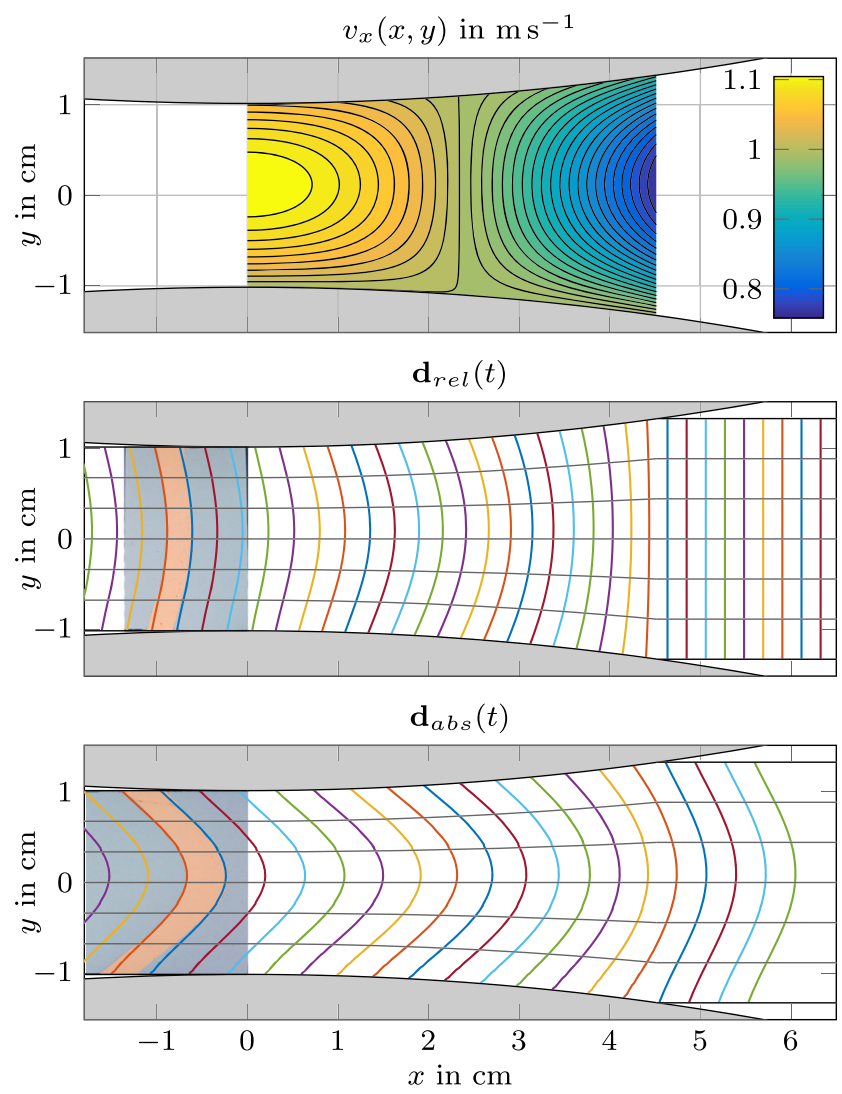

Fig. 8 Velocity field, incremental and absolute deformation after the second roll pass calculated with friction coefficients $\gamma_{u}=0.8$ and $\gamma_{l}=0$

this section is concluded with the results for the absolute deformation after seven roll passes. Clearly, this calculated deformation profile contains the accumulated errors of all previously calculated roll passes. In Fig. 10, the detected front, back, and mean edge of the coper pin after seven roll passes are shown together with the calculated deformation
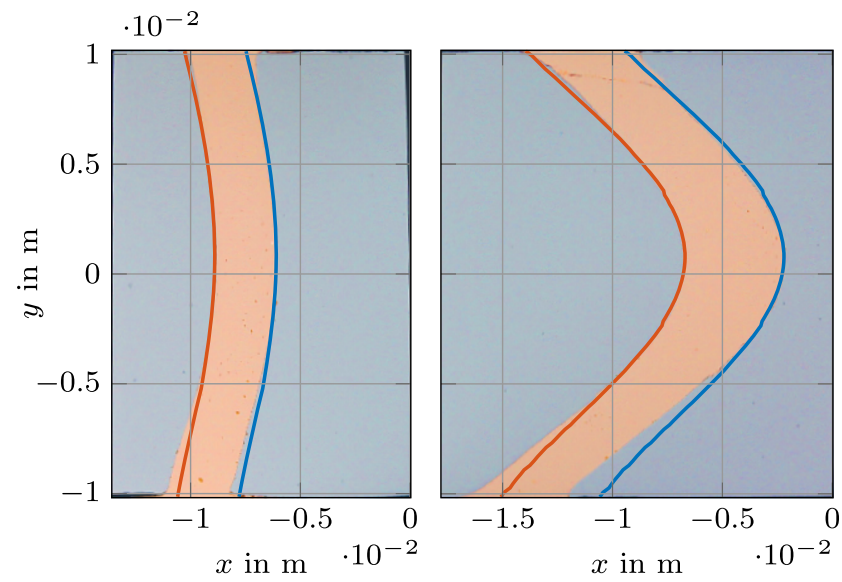

Fig. 9 Calculated incremental and absolute deformation and pictures of the deformed copper pins after the second roll pass 


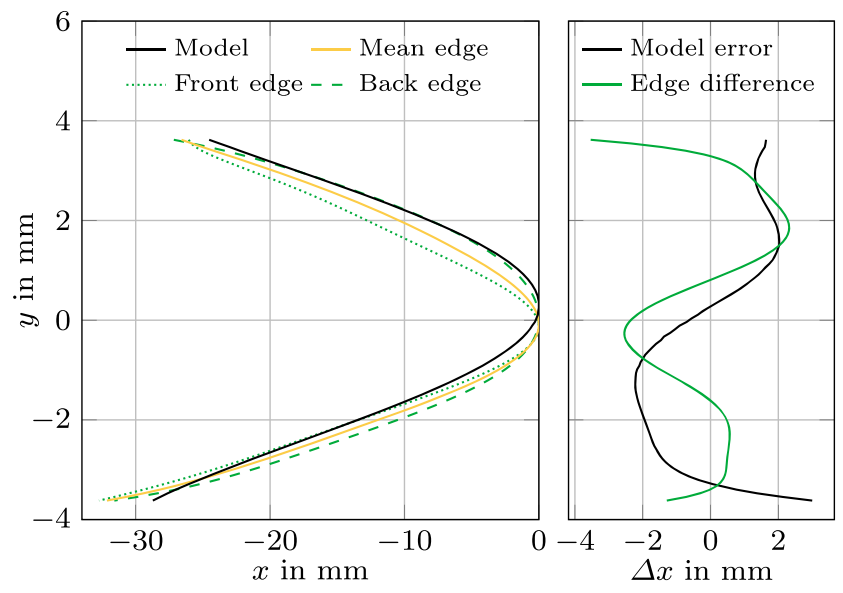

Fig. 10 Detected edges and calculated deformation after seven reductions

profile. The maximum horizontal deflection of the mean edge is $32.14 \mathrm{~mm}$. The error between the calculated and the measured mean deformation profile is also shown in Fig. 10. The maximum model error is $3 \mathrm{~mm}$ and is located at the bottom surface of the strip. In this region, the biggest edge uncertainty in the picture occurred due to the previously mentioned outflow of copper. Neglecting this near-surface region, the maximum model error is $2.22 \mathrm{~mm}$, which gives an accumulated relative error of $6.91 \%$ after seven passes. A comparison with the deviation between the identified front and back edge, which is also given in Fig. 10, shows that the model error is in the same range. The asymmetry caused by different friction at the upper and lower contact surface is also captured by the model with good accuracy.

\section{Summary and outlook}

In this paper, a hydrodynamic roll gap model with separate friction coefficients for the upper and lower strip-roll contact surface was proposed. As the model can be analytically solved, it is well suited for online applications in strip rolling. The field of application for this model ranges from identification or monitoring of current friction conditions to the design of model-based controllers. In particular the online identification of varying friction coefficients combined with feedforward control for the mill adjustment could be an interesting application. In addition to the consideration of asymmetric friction, an advantage of this model is that the influence of the rolling speed on the roll force is systematically taken into account.

For validation of the proposed hydrodynamic roll gap model, a rolling experiment was carried out. To establish asymmetric rolling conditions, upper and lower work rolls with different roughness values were used. A steel strip with copper pins inserted was rolled to visualize the material deformation in the roll gap. The deformation profiles calculated by the asymmetric hydrodynamic roll gap model are in good agreement with the deformation of the copper pins. The maximum accumulated profile error after seven roll passes is $6.91 \%$.

Acknowledgements Open access funding provided by TU Wien. The authors kindly express their gratitude to voestalpine Stahl $\mathrm{GmbH}$ for the realization of the industrial experiments.

Funding information This work was supported by the Austrian Federal Ministry for Digital and Economic Affairs and the National Foundation for Research, Technology and Development, and voestalpine Stahl $\mathrm{GmbH}$.

Open Access This article is distributed under the terms of the Creative Commons Attribution 4.0 International License (http:// creativecommons.org/licenses/by/4.0/), which permits unrestricted use, distribution, and reproduction in any medium, provided you give appropriate credit to the original author(s) and the source, provide a link to the Creative Commons license, and indicate if changes were made.

Publisher's Note Springer Nature remains neutral with regard to jurisdictional claims in published maps and institutional affiliations.

\section{References}

1. Prinz K, Steinboeck A, Müller M, Ettl A, Kugi A (2017) Automatic gauge control under laterally asymmetric rolling conditions combined with feedforward. IEEE Trans Ind Appl 53(3):2560 2568. https://doi.org/10.1109/TIA.2017.2660458

2. Prinz K, Steinboeck A, Kugi A (2018) Optimization-based feedforward control of the strip thickness profile in hot strip rolling. J Process Control 64:100-111. https://doi.org/10.1016/j. jprocont.2018.02.001

3. Montmitonnet P, Fourment L, Ripert U, Ngo QT, Ehrlacher A (2016) State of the art in rolling process modelling. BHM Bergund Hüttenmännische Monatshefte 161(9):396-404. https://doi. org/10.1007/s00501-016-0520-4

4. Lenard JG, Pietrzyk M (1992) Rolling process modelling. In: Numerical modelling of material deformation processes. Springer, London, pp 274-302. https://doi.org/10.1007/978-1-4471-1745$2 \_11$

5. Lenard JG (2007) Primer on flat rolling, 1st edn. Elsevier, New York. https://doi.org/10.1016/b978-0-08-045319-4.x5000-1

6. von Kármán T (1925) Beitrag zur Theorie des Walzvorganges. Z Angew Math Mech 5:139-141

7. Siebel E (1925) Kräfte und Materialfluss bei der bildsamen Formänderung. Stahl Eisen 45:1563-1566

8. Orowan E (1943) The calculation of roll pressure in hot and cold flat rolling. Proc Inst Mech Eng 150(1):140-167. https://doi.org/10.1243/PIME_PROC_1943_150_025_02

9. Sims RB (1954) The calculation of roll force and torque in hot rolling mills. Proc Inst Mech Eng 168(1):191-200. https://doi.org/10.1243/PIME_PROC_1954_168_023_02

10. Alexander J (1972) On the theory of rolling. Proc R Soc Lond A 326(1567):535-563. https://doi.org/10.1098/rspa.1972.0025

11. Freshwater IJ (1996) Simplified theories of flat rolling-I. The calculation of roll pressure, roll force and roll torque. Int $\mathrm{J}$ Mech Sci 38(6):633-648. https://doi.org/10.1016/S0020-7403(96)80006-3 
12. Chen S, Li W, Liu X (2014) Calculation of rolling pressure distribution and force based on improved Karman equation for hot strip mill. Int J Mech Sci 89:256-263. https://doi.org/10.1016/j. ijmecsci.2014.09.011

13. Li WG, Liu C, Liu B, Yan BK, Liu XH (2017) Modeling friction coefficient for roll force calculation during hot strip rolling. Int J Adv Manuf Technol 92(1):597-604. https://doi.org/10.1007/ s00170-017-0188-2

14. Hwang YM, Tzou GY (1993) An analytical approach to asymmetrical cold strip rolling using the slab method. J Mater Eng Perform 2(4):597-606. https://doi.org/10.1007/BF02661746

15. Hensel A, Spittel T (1978) Kraft- und Arbeitsbedarf bildsamer Formgebungsverfahren. VEB Deutscher Verlag für Grundstoffindustrie, Leipzig

16. Oh S, Kobayashi S (1975) An approximate method for a threedimensional analysis of rolling. Int J Mech Sci 17(4):293-305. https://doi.org/10.1016/0020-7403(75)90010-7

17. Martins PAF, Barata Marques MJM (1999) Upper bound analysis of plane strain rolling using a flow function and the weighted residuals method. Int J Numer Methods Eng 44(11):1671-1683. https://doi.org/10.1002/(SICI)1097-0207(19990420)44:11<1671:: AID-NME559>3.0.CO;2-2

18. Komori K (2002) An upper bound method for analysis of threedimensional deformation in the flat rolling of bars. Int J Mech Sci 44(1):37-55. https://doi.org/10.1016/S0020-7403(01)00086-8

19. Kiefer T, Kugi A (2008) An analytical approach for modelling asymmetrical hot rolling of heavy plates. Math Comput Modell Dyn Syst 14(3):249-267. https://doi.org/10.1080/138739 50701844915

20. Liu YM, Ma GS, Zhao DW, Zhang DH (2015) Analysis of hot strip rolling using exponent velocity field and MY criterion. Int J Mech Sci 98:126-131. https://doi.org/10.1016/j.ijmecsci.2015. 04.017

21. Zhang DH, Liu YM, Sun J, Zhao DW (2016) A novel analytical approach to predict rolling force in hot strip finish rolling based on cosine velocity field and equal area criterion. Int $\mathrm{J}$ Adv Manuf Technol 84(5-8):843-850. https://doi.org/10.1007/ s00170-015-7692-z

22. Peng W, Zhang D, Zhao D (2017) Application of parabolic velocity field for the deformation analysis in hot tandem rolling. Int J Adv Manuf Technol 91(5):2233-2243. https://doi.org/10.1007/ s00170-016-9936-y

23. Kobayashi S, Oh S, Altan T (1989) Metal forming and the finite-element method. Oxford series on advanced manufacturing. Oxford University Press, New York

24. Park JJ, Oh SI (1990) Application of three dimensional finite element analysis to shape rolling processes. J Eng Ind 112(1):3646. https://doi.org/10.1115/1.2899293

25. Zhang SH, Zhang GL, Liu JS, Li CS, Mei RB (2010) A fast rigid-plastic finite element method for online application in strip rolling. Finite Elem Anal Des 46(12):1146-1154. https://doi.org/10.1016/j.finel.2010.08.005

26. Alexander JM (1955) A slip line field for the hot rolling process. Proc Inst Mech Eng 169(1):1021-1030. https://doi.org/10.1243/PIME_PROC_1955_169_103_02
27. Dewhurst P, Collins IF (1973) A matrix technique for constructing slip-line field solutions to a class of plane strain plasticity problems. Int J Numer Methods Eng 7(3):357-378. https://doi.org/10.1002/nme.1620070312

28. Kneschke A (1954) Hydrodynamische Theorie des Walzvorganges. Z Bergakad 6(1):1-11

29. Li S, Wang Z, Liu C, Ruan J, Xu Z (2017) A simplified method to calculate the rolling force in hot rolling. Int J Adv Manuf Technol 88(5):2053-2059. https://doi.org/10.1007/s00170-016-8890-z

30. Li S, Wang Z, Ruan J, Liu C, Xu Z (2017) Hydrodynamics method and its application in hot strip rolling. Steel Res Int 88(4):1600220. https://doi.org/10.1002/srin.201600220

31. Weber KH (1963) Erfassung der walztechnischen Kenngrößen nach Gesichtspunkten der hydrodynamischen Walztheorie beim Walzen von Flachquerschnitten. Freiberg. Forschungsh B 91:1-80

32. Kneschke A, Bandemer H (1964) Eindimensionale Theorie des Walzvorganges. Freiberg. Forschungsh B 94:9-75

33. Kiefer T, Heeg R, Kugi A (2005) Feedforward control strategies for hot rolling in a reversing plate mill. PAMM 5(1):165-166. https://doi.org/10.1002/pamm.200510062

34. Heeg R, Kiefer T, Kugi A, Fichet O, Irastorza L (2007) Feedforward control of plate thickness in reversing plate mills. IEEE Trans Ind Appl 43(2):386-394. https://doi.org/10.1109/ TIA.2006.890027

35. Cristescu N (2007) Fast material working: Wire drawing. In: Advanced methods in material forming. Springer, Berlin, pp 199 214. https://doi.org/10.1007/3-540-69845-0_12

36. Hitchcock J (1935) Roll neck bearings. ASME Res Publ, pp 33-41

37. Kneschke A (1958) Zur hydrodynamischen Theorie des Warmwalzens. Arch Eisenhüttenwes 29(1):11-22. https://doi.org/ 10.1002/srin. 195802221

38. Roberts WL (1978) Cold rolling of steel. Manufacturing engineering and materials processing. Taylor \& Francis, New York

39. Geleji A (1960) Bildsame Formung der Metalle in Rechnung und Versuch. Akademie-Verlag, Berlin

40. Weber KH (1966) Stand der hydrodynamischen Walztheorie. Arch Eisenhüttenwes 37(10):783-794. https://doi.org/10.1002/ srin. 196604287

41. Müller M, Steinboeck A, Prinz K, Kugi A (2018) Optimal parameter identification for a hydrodynamic roll gap model in hot strip rolling. In: Proceedings of the 5th IFAC Workshop on Mining, Mineral and Metal Processing (MMM). Shanghai

42. Colas R (1995) Modelling heat transfer during hot rolling of steel strip. Model Simul Mater Sci Eng 3(4):437. https://doi.org/ 10.1088/0965-0393/3/4/002

43. Koohbor B, Moaven K (2017) Finite-element modeling of thermal aspects in high speed cold strip rolling. Proc Inst Mech Eng B: J Eng Manuf 231(8):1350-1362. https://doi.org/10.1177/ 0954405415592198

44. Speicher K, Steinboeck A, Kugi A, Wild D, Kiefer T (2014) Analysis and design of an extended kalman filter for the plate temperature in heavy plate rolling. J Process Control 24(9):13711381. https://doi.org/10.1016/j.jprocont.2014.06.004 